\title{
Potential adverse effects of nanoparticles on the reproductive system
}

This article was published in the following Dove Press journal: International Journal of Nanomedicine

\author{
Ruolan Wang' \\ Bin Song ${ }^{2}$ \\ Junrong $\mathrm{Wu}^{\prime}$ \\ Yanli Zhang' \\ Aijie Chen' \\ Longquan Shaol,3
}

'Nanfang Hospital, Southern Medical University, Guangzhou 5I05I5, China; ${ }^{2}$ Guizhou Provincial People's Hospital, Guiyang 550002, China; ${ }^{3}$ Guangdong Provincial Key Laboratory of Construction and Detection in Tissue Engineering, Guangzhou 5I05I5, China
Correspondence: Longquan Shao Nanfang Hospital, Southern Medical University, 1838 North Guangzhou Avenue, Guangzhou 510515, China $\mathrm{Tel}+86$ I598928392I

Email shaolongquan@smu.edu.cn

\begin{abstract}
With the vigorous development of nanometer-sized materials, nanoproducts are becoming widely used in all aspects of life. In medicine, nanoparticles (NPs) can be used as nanoscopic drug carriers and for nanoimaging technologies. Thus, substantial attention has been paid to the potential risks of NPs. Previous studies have shown that numerous types of NPs are able to pass certain biological barriers and exert toxic effects on crucial organs, such as the brain, liver, and kidney. Only recently, attention has been directed toward the reproductive toxicity of nanomaterials. NPs can pass through the blood-testis barrier, placental barrier, and epithelial barrier, which protect reproductive tissues, and then accumulate in reproductive organs. NP accumulation damages organs (testis, epididymis, ovary, and uterus) by destroying Sertoli cells, Leydig cells, and germ cells, causing reproductive organ dysfunction that adversely affects sperm quality, quantity, morphology, and motility or reduces the number of mature oocytes and disrupts primary and secondary follicular development. In addition, NPs can disrupt the levels of secreted hormones, causing changes in sexual behavior. However, the current review primarily examines toxicological phenomena. The molecular mechanisms involved in NP toxicity to the reproductive system are not fully understood, but possible mechanisms include oxidative stress, apoptosis, inflammation, and genotoxicity. Previous studies have shown that NPs can increase inflammation, oxidative stress, and apoptosis and induce ROS, causing damage at the molecular and genetic levels which results in cytotoxicity. This review provides an understanding of the applications and toxicological effects of NPs on the reproductive system.
\end{abstract}

Keywords: nanoparticles, toxic, reproductive, sperm, ovary, ROS

\section{Introduction}

Nanomaterials (NMs) contain 50\% or more nanoparticles (NPs; in number or size distribution) with one or more external dimensions in the size range of $1-100 \mathrm{~nm} .{ }^{1}$ Because of the small size of NPs, they exhibit novel mechanical, electrical, optical, thermal, and magnetic properties. ${ }^{2}$ NPs have been widely used in all aspects of life, including biology, pharmacology, medicine, chemistry, physics, material science, engineering, and industry, but NPs can also be found in cosmetics and products that are used daily, such as clothes and food. The growing demand for NMs and nanoenabled devices worldwide was expected to reach approximately $\$ 3.1$ trillion by $2015,{ }^{3}$ which would increase the risk of human exposure to NPs. The broad applications of NMs have raised concerns about their biological effects. Indeed, studies have shown that NPs are likely to have toxic effects on many organs, such as the brain, liver, and lungs, which are the most studied target organs.

Reproductive toxicity is increasingly becoming recognized as an important part of overall toxicology. However, the reproductive toxicity of NPs has not been studied in depth until very recently. Reproductive physiology involves a series of complex 
physiological processes that are sensitive to chemical contaminants. Current studies have shown that the incidence of testicular dysgenesis syndromes, including low sperm production in adulthood, cryptorchidism, hypospadias, and testicular cancer, is increasing. ${ }^{4}$ This increased incidence of male reproductive diseases may be partly attributable to environmental contaminant exposure.

Exposure to NPs may result in critical toxicity during the development of the reproductive system. In addition, the administration of NiNPs to adult female rats profoundly disrupted the functions of the reproductive system, as evidenced by injured uterine and ovarian tissues and disruption of follicle-stimulating hormone (FSH), luteinizing hormone (LH), and estradiol (E2) excretion, resulting in abnormal births. This review investigates the reproductive toxicity caused by NPs and examines the mechanisms involved in this process.

\section{Reproductive system and its function}

The reproductive system or genital system comprises the sex organs within an organism which work together for sexual reproduction. Many nonliving substances such as fluids, hormones, and pheromones are also important influencers of the reproductive system. In contrast to most organ systems, the reproductive system often exhibits significant differences between the sexes of differentiated species. These differences allow for a combination of genetic material between two individuals, which improves the genetic fitness of the offspring.

\section{Male reproductive system and its function}

The male reproductive system comprises reproductive organs and glands, including external genitalia and internal genitalia. The external genitalia are located outside the body and include the penis, scrotum, and testicles. In addition, internal genitalia are located inside the body and include the epididymis, conducting framework (vas deferens, ejaculatory ducts, urethra, seminal vesicles), and specific glands (prostate gland, bulbourethral glands).

The main function of the male reproductive system is to produce, maintain, and transport sperm and protective fluid and discharge the sperm in the female reproductive tract during sex. To maintain the male reproductive system, the reproductive organs and glands need to secrete sex hormones.

\section{Female reproductive system and its function}

The female reproductive system is also composed of reproductive organs and glands. However, unlike the male reproductive system, most of the female genitalia are located inside the body. The external genitalia include the labia majora, labia minora, Bartholin's glands, and clitoris. In addition, the internal reproductive organs in the female include the vagina, uterus, ovaries, and fallopian tubes.

The female reproductive system is made to fulfill several functions. The most basic function is producing the female ova or oocytes that function as egg cells; this activity is crucial for reproduction. The second function of the female reproductive system is to transport the eggs to the site of fertilization. The most important function is conception, which generally occurs in the fallopian tubes when an oocyte is fertilized by sperm. The next step is for the fertilized egg to implant into the uterine wall and begin the early stages of pregnancy. If fertilization and/or implantation does not occur, the system will menstruate. In addition, female sex hormones are produced to maintain the reproductive cycle.

\section{Routes of NP entry into the reproductive system \\ Direct path of NP entry into the reproductive system}

NPs can be used as drugs and drug delivery vehicles and for fluorescence imaging in the reproductive system. NMs used as a drug carrier for targeted therapy directly combine with target organs or target cells, providing an opportunity for NMs to enter the reproductive system directly. Ultrasensitive molecular imaging nanoprobes can be used to detect targeted biological structures. ${ }^{5}$ AuNPs are a reliable labelfree contrast agent for visualizing NIH OVCAR-3 (ovarian cancer cells). ${ }^{6}$ In addition, other NPs can be used to treat certain diseases. The tocotrienol nanoemulsion platform of curcumin can be used to treat breast and ovarian carcinoma. ${ }^{7}$ Fatty acid/poly(lactic-co-glycolic acid) NPs used as a drug delivery system enhance the in vitro cytotoxicity and in vivo targeting potential of paclitaxel against ovarian cancer stem cells. ${ }^{8}$

\section{Indirect path of NP entry into the reproductive system \\ Absorption of NPs}

There are three main exposure routes, such as dermal exposure, pulmonary exposure, and gastrointestinal exposure, in 
addition to others. Skin exposed to NPs present in cosmetic products has been suggested as a potential route for drug delivery involving nanocarriers. ${ }^{9}$ However, the dermal absorption of nano-titanium dioxide in vivo and in vitro has been found to be very low, generally below the detection level. ${ }^{10-14}$ Thus, NPs can be absorbed through the skin without causing substantial toxicity.

Previous studies have revealed that gastrointestinal exposure is one of the important NP absorption pathways. Many articles have reported that multiple NPs can be absorbed from the gastrointestinal tract into the bloodstream and deposited in secondary organs. NPs are often used in foods and beverages. Since 2007, nearly 72 food and beverage products have been reported to contain NPs. ${ }^{15}$ Multiple NP types, such as AgNPs, silica $\mathrm{SiO}_{2} \mathrm{NPs}, \mathrm{TiO}_{2} \mathrm{NPs}$, and $\mathrm{ZnO}$ NPs, are added to food and drugs as ingredients. This trend might be highly relevant for oral ingestion of NPs. As a result, many NPs can be consumed orally and enter the body through the gastrointestinal tract, but the absorptivity of each substance is different. Based on the existing literature, it is estimated that the daily ingestion ranges for several NPs are 0.008- $0.032 \mu \mathrm{g} / \mathrm{mL}$ for AgNPs, $9.3-50.4 \mu \mathrm{g} / \mathrm{mL}$ for $\mathrm{SiO}_{2}$ NPs, and $0.12-12.6 \mu \mathrm{g} / \mathrm{mL}$ for $\mathrm{TiO}_{2} \mathrm{NPs}^{16}$ In addition to different absorption rates, the residence times of these substances also differ. Nanosized substances generally spend the longest time in the large intestine but the shortest time in the stomach, which may explain their different absorptivity values. The absorption rate of $\mathrm{TiO}_{2}$ particles is approximately $0.06 \%-4 \%$ and is lowest in the stomach and highest in the large intestine. After NPs are absorbed, they can be redistributed and deposited in different organs and tissues. ${ }^{17}$ The liver, spleen, and mesenteric lymph nodes have been selected as priority target organs for oral administration. ${ }^{18}$ Nanosized cerium oxide particles were mostly observed to be retained in the lung tissue via inhalation. ${ }^{19}$ Inhalation studies of some NPs have confirmed that some inhaled substances are transferred to extrapulmonary organs. For example, NPs can enter the central nervous system through olfactory neurons and cause an inflammatory response. ${ }^{20}$

\section{Translocation/deposition of NPs}

After dermal, pulmonary, and gastrointestinal exposure, NPs can be absorbed into the blood. Generally, NPs are rapidly absorbed in the blood and distributed to tissues. ${ }^{21-24}$ Current studies have shown that NPs first enter and distribute in the exposed site after exposure of animals to NPs via inhalation, ingestion, or injection, and then, they translocate to secondary organs, such as the liver, spleen, kidneys, brain, ovaries, and testes; traces of these NPs have also been detected in the blood and urine. ${ }^{2}$ Mononuclear phagocytic cells possess a nonspecific immune defense function and swallow and digest foreign substances. NPs as foreign substances can be taken up by mononuclear phagocytic cells, which is the main route by which NPs enter tissues and cells. Some circulatory proteins can bind NPs to the blood and increase the rate of phagocytosis. ${ }^{20}$ Animal and human studies have shown that macrophage clearance is the main reason NPs can translocate through the circulatory and lymphatic system to many tissues and organs. ${ }^{25}$ After translocation through circulation, NPs can permeate some biological membranes and accumulate in reproductive organs. Studies have revealed that some of the most promising NPs demonstrate prolonged tissue residence. ${ }^{26}$

NPs can cross biological barriers, including the barriers that protect reproductive tissue. ${ }^{27}$ Several studies have demonstrated that various NPs can pass through the blood-testis barrier (BTB) and exert their toxic actions on spermatogenesis. ${ }^{28}$ Regarding deposition and translocation, the ability of NPs to cross both the blood-brain barrier and the BTB is highly important. ${ }^{29,30}$ However, specific physical and chemical properties of NPs (ie, size, shape, and polarity) may allow for their passage through these biological barriers, ${ }^{2}$ but the underlying mechanism remains unclear. One study attempted to investigate the mechanisms by which $\mathrm{ZnO}$ NPs exert reproductive effects using a mouse Sertoli cell line (TM-4) and spermatocyte cell line (GC2-spd). Liu et $\mathrm{al}^{13}$ suggested that $\mathrm{ZnO}$ NPs can induce ROS and cause DNA lesions in germ cells. ZnO NPs could impair the BTB by downregulating the expression of gap junction proteins and disrupting the cell membrane and mitochondrial outer membrane in Sertoli cells, potentially leading to BTB injury and further destroying BTB integrity. Furthermore, ROS and the secretion of cytokines play important roles in BTB disruption, significantly increasing the oxidative stress status (ie, leading to increased ROS and malondialdehyde levels and decreased glutathione levels) and increasing the cytokine (TNF- $\alpha$ ) levels in Sertoli cells.

In addition to the adverse effect on reproductive system of parental, NPs can also affect the development of the offspring. Hydrophilic molecules and particles above $1 \mathrm{kDa}$ are usually unable to cross the placental barrier. However, some studies have shown otherwise. NPs can cross the placental barrier, and increasing evidence suggests that particle characteristics and functionalization can, to some extent, 
affect particle transfer. ${ }^{32}$ Philbrook et al ${ }^{33}$ identified AgNPs using transmission electron microscopy (TEM) in the fetal livers and kidneys of mouse dams after orally taken AgNPs. However, different opinions exist regarding whether NPs can penetrate the placental barrier. ${ }^{34}$ Recent research has indicated that certain NPs can reach the fetal circulation and accumulate in fetal organs. For some NPs, evidence indicates potential teratogenic effects, but whether these effects are caused by the translocated particles or a release of maternal or placental mediators remains unclear..$^{32}$ Myllynen's study showed that gold NPs can pass through the placental barrier. ${ }^{94}$ However, NPs could not be detected in the fetus.

\section{Male reproductive toxicity of NPs}

Previous studies have shown that NPs can accumulate in the testis prostate gland and epididymis via blood circulation or direct contact with NPs, causing cytotoxicity. In males, the testis and epididymis are the main targets of NPs in the genital area, and research has shown that most of the NPs can reach male mouse reproductive organs or tissues, such as the testis, epididymis, and seminiferous tubule, through different routes. ${ }^{35}$ One study concluded that nanosized $\mathrm{TiO}_{2}$ had severe toxic effects on the reproductive system in male rats. Oral administration of nanosized $\mathrm{TiO}_{2}$ alone resulted in marked changes in body weight and the relative weights of the testis and accessory male sex organs in a time-dependent manner. ${ }^{36}$ The reproductive toxicity of NPs has been demonstrated in many reports. However, other studies have reported contrasting results. After intramuscular injection of well-characterized $70 \mathrm{~nm}$ gold core-silica shell NPs in mice, no particles were found to reach the testes. ${ }^{37}$ In this article, we discuss the male reproductive toxicity of NPs in terms of the following aspects (Figure 1).

\section{Effect on reproductive organs (potential adverse effects on reproductive organs)}

Kim et a ${ }^{30}$ showed that $50 \mathrm{~nm}$ magnetic NPs can penetrate the mouse BTB. Thus, NPs can pass through the BTB and be deposited in the testes and other reproductive organs, further affecting these organs. In male rats, the weights decreased gradually, and the ratio of the epididymis weight to the body weight increased after gavage with nickel NPs.$^{38}$ However, Garcia reported that the intravenous injection of AgNPs in male CD1 mice resulted in no changes in the body and testis weights. ${ }^{39}$ These contrasting results may be attributable to the use of different types of NPs. Indeed, some substances may cause these types of changes, whereas others might not. Another change in reproductive organs was observed in some experiments. Histological examination revealed that graphene oxide exposure was associated with structural damage in the testicles, but the alteration in structure showed recovery within 30 days..$^{40}$ Gold alloys might induce the inflammation of the epididymis, which is important because the inflammation decreases sperm motility. ${ }^{41}$ Alterations in the testis seminiferous tubule morphometry in rats treated with $200 \mathrm{~nm} \mathrm{AgNPs}$ were observed. $\mathrm{CeO}_{2} \mathrm{NPs}$ could also lead to congestion and degeneration of seminiferous tubules. ${ }^{42}$ Another study showed that $\mathrm{nSP} 70$ could penetrate the BTB and nuclear membranes

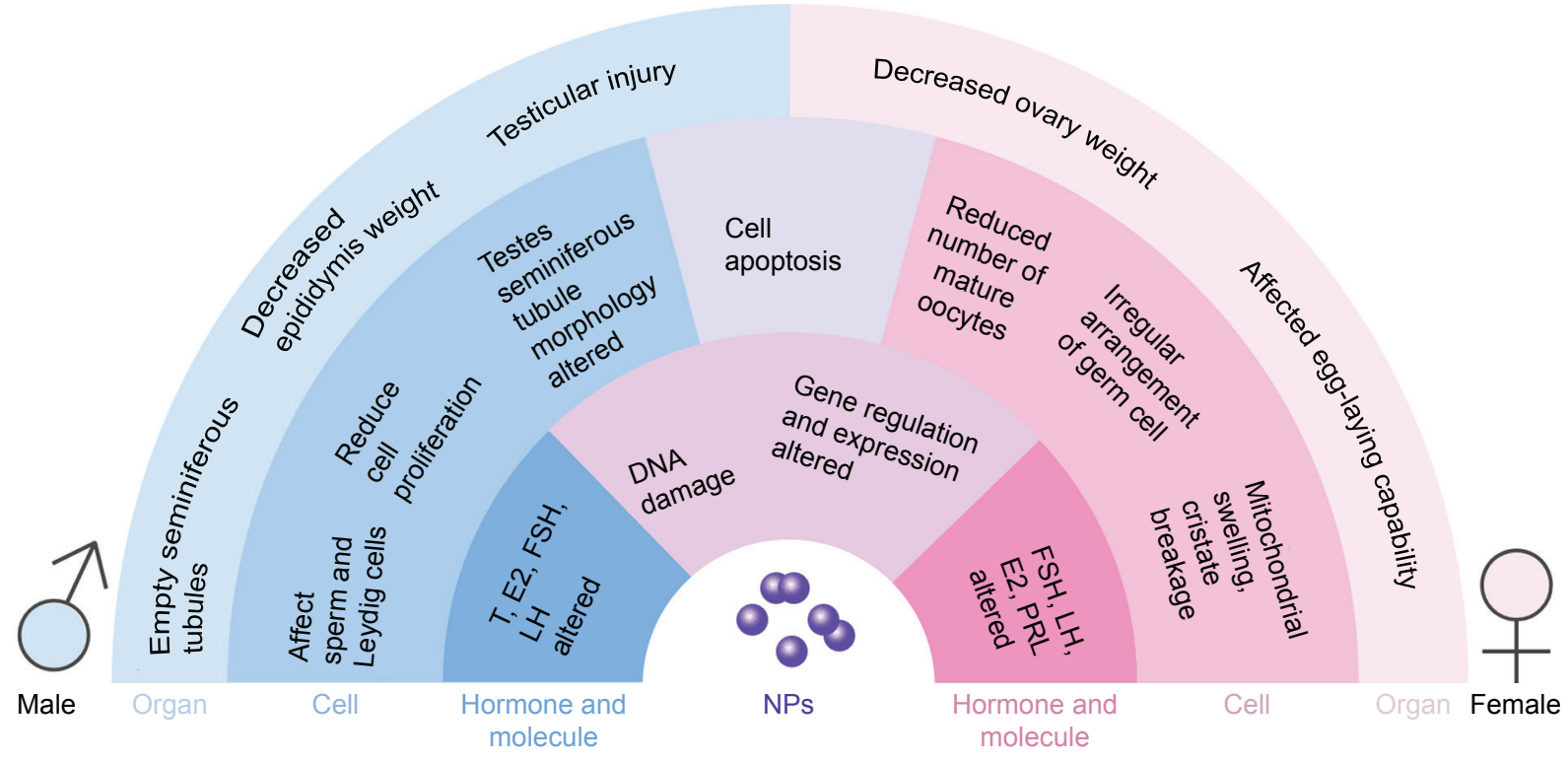

Figure I Adverse effect of NPs in the reproductive cell organs and molecules.

Abbreviations: E2, estradiol; FSH, follicle-stimulating hormone; LH, luteinizing hormone; NPs, nanoparticles; PRL, prolactin; T, testosterone. 
of sperm cells without producing significant testicular damage. ${ }^{43}$ Amorphous nanosilica particles (nSPs) can penetrate the BTB and the nuclear membranes of spermatocytes without producing significant testicular damage. ${ }^{44}$

In addition to morphological changes, some marker changes were also found. $\mathrm{TiO}_{2}$ NPs could significantly increase serum prostate-specific antigen level and serum prostatic acid phosphatase (PAP) activity. ${ }^{45}$ In addition, intragastric administration of $\mathrm{TiO}_{2}$ NPs significantly increased the activity of the testicular marker enzyme $\gamma$-Glutamate transpeptidase $(\gamma-\mathrm{GT})$ and acyl carrier protein (ACP) activity. Another study showed an increase in serum PSA concentration after treatment with $\mathrm{ZnO} N \mathrm{NPs}^{46}$ PAP concentrations may be related to benign prostatic hyperplasia, prostatic infarction, and manipulation of the prostate gland. ${ }^{47} \gamma$-GT and ACP activity might be related to impaired spermatogenesis. ${ }^{48}$ The increased prostate specific antigen and $\gamma$-GT levels and increased activity of PAP and ACP might indicate injury of the prostate and testes.

The toxicity of NPs in the testicles depends on the particle dose and type; however, the salt solubility has no significant positive effects. It seems that AgNPs are the most toxic. In addition, particle size is a critical factor in the nanotoxic effects on the reproductive system.

\section{Effect on germ cells}

Effect on sperm (potential reversible adverse effect on sperm count morphology and dynamics)

Much research has shown that NPs can pass through the BTB and cause changes in sperm morphology and decrease the number and viability of sperm. However, the impact varies from species to species and according to different types of NPs. One study showed that injecting Wistar mice with AgNPs via the tail vein led to an apparent decrease in the sperm count. In addition to the decline in number, morphological changes were also observed. Folded, amorphous spermatozoa, cells lacking or showing a small hook, and cells with undulating or elongated heads were the most frequent abnormalities found. However, no difference was observed between different dose groups or sizes. ${ }^{43,49}$ Another study showed significant decreases in sperm motility and live percentage and the development of abnormal sperm after treatment with $\mathrm{ZnO}$ NPs. In addition, increasing the dose led to greater toxicity. ${ }^{42}$ In Taylor et al' ${ }^{34}$ study, a decrease in sperm motility and severe morphological defects in treated spermatozoa were observed after gold NP exposure. However, in that study, the decrease in motility was not accompanied by an increase in abnormal sperm morphologies or impaired membrane integrity. In Chen's study,${ }^{95}$ the acrosome integrity of the sperm from AgNP-treated animals was impaired. Another study demonstrated that nanotubes can accumulate in the testes, ultimately generating oxidative stress and decreasing the thickness of the seminiferous epithelium in the testes. However, this type of sperm toxicity might be reversible via the metabolism of the germinal epithelium. ${ }^{50}$ All the above-mentioned articles revealed that various NPs can exert adverse effects on both the quality and quantity of sperm. All of these works reported a decreased sperm count and abnormal morphology, but some studies have shown that this type of toxicity can be reversed by metabolism.

\section{Effect on other cells (potential adverse effect on other cells)}

NPs have been reported to not only affect sperm but also alter the viability, proliferation, and gene expression of Leydig cells. ${ }^{51}$ One study found that AgNPs can reduce cellular proliferation in mammalian spermatogonial stem cells (SSCs) in vitro and might lead to decreased fertility in vivo. An in vivo study revealed that AgNPs can significantly change the epithelial morphology, germ cell apoptosis, and Leydig cell size and increase the level of DNA damage in germ cells. ${ }^{39,43,52} \mathrm{~A}$ high concentration of graphene can be toxic to SSCs. However, surface modification can reduce this toxicity. ${ }^{53}$ Shedding of epithelial cells from raw seminiferous tubules, disordered arrangement of cells in the tube, and the appearance of cells were observed after the administration of nickel NPs via gavage. ${ }^{38}$ Another study showed that after $\mathrm{ZnO}$ treatment, degenerative changes, atrophy, and necrosis were observed in most seminiferous tubules. These changes increased gradually as the dose was increased. At a dose of $300 \mathrm{mg} / \mathrm{kg}$, focal mild testicular degeneration of single or several layers of vacuolated spermatocytes near congested interstitial blood vessels was found. Few desquamated spermatocytes were seen in the lumen of some seminiferous tubules. In contrast, at $400 \mathrm{mg} / \mathrm{kg}$, shrunken, disorganized seminiferous tubules with irregular basement membranes and incomplete spermatogenesis were observed. Some tubules showed coagulative necrosis, and the seminiferous tubules were almost empty of spermatids and spermatozoa. ${ }^{28}$

\section{Effect on hormone levels}

Some hormone levels have been reported to change after exposure to some NPs. One study showed that when lowdose (1 mg/kg/dose) AgNPs were intravenously injected into male CD1 mouse serum, the intratesticular testosterone (T) concentrations increased significantly. ${ }^{39}$ In another study, the 
serum $T$ level decreased significantly after treatment with ZnO NPs but increased significantly after supplementation with quercetin..$^{54}$ After treatment with $\mathrm{CeO}_{2} \mathrm{NPs}$, decreases in $\mathrm{T}, \mathrm{FSH}, \mathrm{LH}$, and prolactin (PRL) were discovered. ${ }^{42}$ However, another study revealed that the T, E2, FSH, and LH profiles were not altered by AgNP treatment, and the serum concentrations of FSH, LH, T, and E2 did not differ significantly between the experimental groups treated with different doses of AgNPs (15 and $30 \mu \mathrm{g} / \mathrm{kg}$ ). ${ }^{55}$ No unified theory about how hormone levels change after exposure to NPs exists. Indeed, these changes might be influenced by different factors, such as particle type, size, and time of exposure. Furthermore, hormone levels might be regulated by the hypothalamic-pituitary-testis axis. Serum concentrations of T, progesterone (P4), corticosterone, and FSH and testicular concentrations of steroidogenic acute regulatory protein and $17 \beta$-hydroxysteroid dehydrogenase mRNA were decreased after exposure to nanoparticle-rich diesel exhaust (NR-DE) or filtered diesel exhaust (F-DE). In contrast, serum concentrations of immunoreactive inhibin were increased after exposure to NR-DE or F-DE, whereas transcription of FSH receptor mRNA was only increased in the NR-DE exposure group..$^{56}$ Most of the results showed a decrease in $\mathrm{T}$, which might result in testis injury, and the negative feedback effect might be related to a rise in LH and FSH levels. Another possible way that NPs could affect hormones is that NPs might impact the hypothalamus and pituitary and cause a decrease in LH and FSH secretion. A reduction in LH and FSH would then reduce $\mathrm{T}$ levels. This might be the reason why the results were inconsistent. However, further research of how NPs affect hormones should be conducted. The lack of in vitro studies is still a problem.

\section{Effect on sexual behavior}

One experiment evaluated several sexual behaviors, including the number of mounts, intromissions, ejaculatory intervals, attempted mounts, and ejaculations and the time to first ejaculation; however, none of these behaviors differed among the experimental groups.$^{55}$ Few reports on the effects of NPs on sexual behavior are available. Thus, further studies about how NPs affect sexual behaviors are needed.

\section{Other effects}

In addition to the changes described earlier, NPs can also alter the molecular and gene expression levels. After exposure to FeNPs, the total protein, aspartate transaminase (AST), alanine transaminase (ALT), and globulin levels increased significantly, whereas the glucose, ALP, and potassium levels clearly decreased..$^{57}$

\section{Female reproductive toxicity of NPs}

One study found that NPs are more likely to accumulate in females, ${ }^{58}$ but the same result is not reported in other works. Accumulation of NPs in rodent ovaries was observed, and this accumulation was determined to be size dependent and limited to special regions of the ovaries. ${ }^{59}$ Thus, NPs can enter the female reproductive system and damage the female reproductive organs and cells, thereby compromising their fertility and fetal development.

However, one study has shown that repeated oral doses of multiwalled carbon nanotubes (MWCNTs) during pregnancy induce minimal maternal toxicity and no embryo-fetal toxicity at $1,000 \mathrm{mg} / \mathrm{kg} /$ day in rats. ${ }^{60}$

\section{Effect on reproductive organs}

NPs adversely affected uterus and ovaries by secondary deposition after blood circulation. Research showed that smaller NPs are better able to accumulate in the uterus. ${ }^{61}$ $\mathrm{ZnO}$ NP exposure before and during pregnancy and lactation could pose health risks to pregnant females and their fetuses. ${ }^{62}$ One study detected the accumulation of NPs, nanocapsules, and nanosized lipid emulsions in specific locations in rodent ovaries. This phenomenon was further characterized by ex vivo fluorescence imaging and confocal laser scanning microscopy. Based on extensive in vivo and ex vivo studies, the enrichment was size dependent. Larger particles seemed to accumulate to a greater extent than smaller ones. Because this accumulation was limited to special regions in the ovaries, the toxic risk for human beings could be rather low. ${ }^{59}$ Some reports have also suggested that NPs deposit in the ovaries and affect reproductive organs. One study reported that decreased ovary weight coefficients were caused by NiNPs. ${ }^{62}$ Short- and long-term exposure of Drosophila to AgNPs during the adult stage significantly affected their egg-laying capability and resulted in impaired ovary growth. ${ }^{63}$

\section{Effect on germ cells}

\section{Effect on follicles}

Titanium dioxide particles cause morphological changes in follicles and may lead to a reduced number of mature oocytes. NPs can affect both primary and secondary follicles by disturbing their development. A shapeless follicular antrum and irregular arrangement of cells were observed, suggesting that the ovaries are damaged by long-term exposure to $\mathrm{TiO}_{2}$ NPs. ${ }^{64}$ Atretic follicles were increased after exposed to nano- $\mathrm{TiO}_{2}{ }^{64}$ However, only a few reports have described how NPs affect follicles, and more experiments should be conducted to confirm these results. 


\section{Effect on other cells}

$\mathrm{TiO}_{2}$ NPs can accumulate in the cytoplasm and nuclei of ovarian cells and induce apoptosis. A previous report showed that after exposure to $\mathrm{TiO}_{2} \mathrm{NPs}$, the ultrastructure of the mitochondria and nuclei of ovarian cells was impaired. Mitochondrial swelling and rupture, nuclear chromatin condensation, and irregularity of the nuclear membrane were observed. ${ }^{64}$ Another study indicated that exposure to nickel NPs resulted in ovarian lymphocytosis, luteal cell increase, and cavitation increased eosinophils and inflammatory cell infiltration in rat ovarian tissues. ${ }^{38}$ Intact NPs were detected in hen ovarian tissues after treatment with ZnO NPs, and treatment significantly decreased the egg yolk lipid content. ${ }^{66}$ All three kinds of NPs could deposit in ovarian cells and further damage these cells at the molecular level and genetic level. These injuries may indirectly affect fertility.

\section{Effect on hormone levels}

As they do in males, NPs can also cause imbalance of sex hormones in females. In females, sex hormones maintain the reproductive cycle, which is crucial for the female reproductive system. The imbalance of sex hormones induced by NPs might affect fertility. Kong reported that NPs increased the serum levels of FSH and LH and lowered the E2 serum level in female rats. ${ }^{38}$ Another study showed that $\mathrm{TiO}_{2} \mathrm{NP}$ exposure caused significant increases in E2 and FSH and reductions in P4, LH, and T; however, the levels of PRL and sex hormone-binding globulin showed no significant changes. ${ }^{64}$ In addition, poly(ethylene glycol)-block-poly(D,L-lactic acid) (PEG- $b$-PLA) increased the weight of the pituitary gland due to hyperemia, vascular dilatation, and congestion, altered hypothalamic gonadotropin-releasing hormonestimulated LH secretion, and increased P4 serum levels. ${ }^{27}$ Therefore, the change in hormone levels might involve a more complicated process. In addition to sex gland secretory hormones, the hypothalamic-pituitary gland axis also plays an important role. Further investigation is required to reveal how NPs affect sex hormones and their underlying mechanisms.

\section{Effect on sexual behavior}

Only a few studies have addressed the effects of NPs on sexual behavior. Rollerova et $\mathrm{al}^{27}$ suggested that PEG- $b$ PLA can disturb the estrous cycle of Wistar rats. Low-dose PEG- $b$-PLA can significantly reduce the number of regular estrous cycles and advance the onset of puberty in a dosedependent manner. In exposed carbon nanotubes to female mice, delivery of the first litter was delayed by an average of 5 days. ${ }^{67}$

\section{Other effects}

Some studies have demonstrated that NPs can affect fetal development, and a review suggests that carbon-based NMs (CNMs) may adversely affect pregnancy and embryonic/fetal development. The data suggest that the size, shape, surface properties and chemistry, concentration, agglomeration, dose, and preparation of CNMs are all determinants of biological activities that may lead to developmental and reproductive toxicity in a dose-dependent manner (the higher the concentration, the greater the toxicity). ${ }^{68}$ In addition, some of the reports showed that NP-induced toxicity can be amplified in the pregnant population. $\mathrm{TiO}_{2} \mathrm{NPs}$ appeared toxic in nonpregnant $\mathrm{BALB} / \mathrm{c}$ mice but led to robust and persistent acute inflammation in pregnant BALB/c mice ${ }^{69}$ Certain NPs injected intravenously into mice did cause placental abnormalities and pregnancy complications depending on particle size and surface chemistry. ${ }^{70}$ One study showed that $\mathrm{MgO}$ NPs produced significant toxicity with genotoxic, biochemical, histopathological, and biodistribution parameters, and they also found elevated levels of MDA and depletion of GSH, catalase (CAT), and superoxide dismutase (SOD), which indicate the occurrence of oxidative stress. Thus, the genotoxicity may be caused by ROS. ${ }^{71}$ Gao et al's ${ }^{64}$ study indicated that $\mathrm{TiO}_{2} \mathrm{NP}$ exposure decreased the fertility and development of young mice. Others showed that NPs can show toxic effects by altering gene expression. Microarray analysis revealed that 223 genes of known function were upregulated in the ovaries of mice treated with $\mathrm{TiO}_{2} \mathrm{NPs}$ compared with their expression in controls, while 65 ovarian genes were downregulated. $\mathrm{TiO}_{2} \mathrm{NPs}$ increased the expression of insulin-like growth factor-binding protein 2, EGF, TNF- $\alpha$, tissue plasminogen activator, IL-1 $\beta$, IL- 6 , Fas, and FasL and significantly decreased the expression of insulinlike growth factor-1, LH receptor, inhibin a, and growth differentiation factor 9 in the mouse ovary ${ }^{65}$ The levels of AST, ALT, ALP, amylase, sodium, potassium, and chloride were remarkably decreased in the blood of female offspring mice, whereas the glucose level was elevated after FeNP exposure (Table 1). ${ }^{57}$

\section{Mechanisms involved in reproductive toxicity}

NPs have been reported to induce reproductive toxicity, but the mechanism is not well understood. The mechanism most reported to underlie the reproductive toxicity of NPs is ROS generation. ROS comprise oxygen species that can damage cells and DNA, and the change in the genetic material may be inherited by the next generation. NPs pass through the outer membranes of gonads and generate ROS in the membranes 


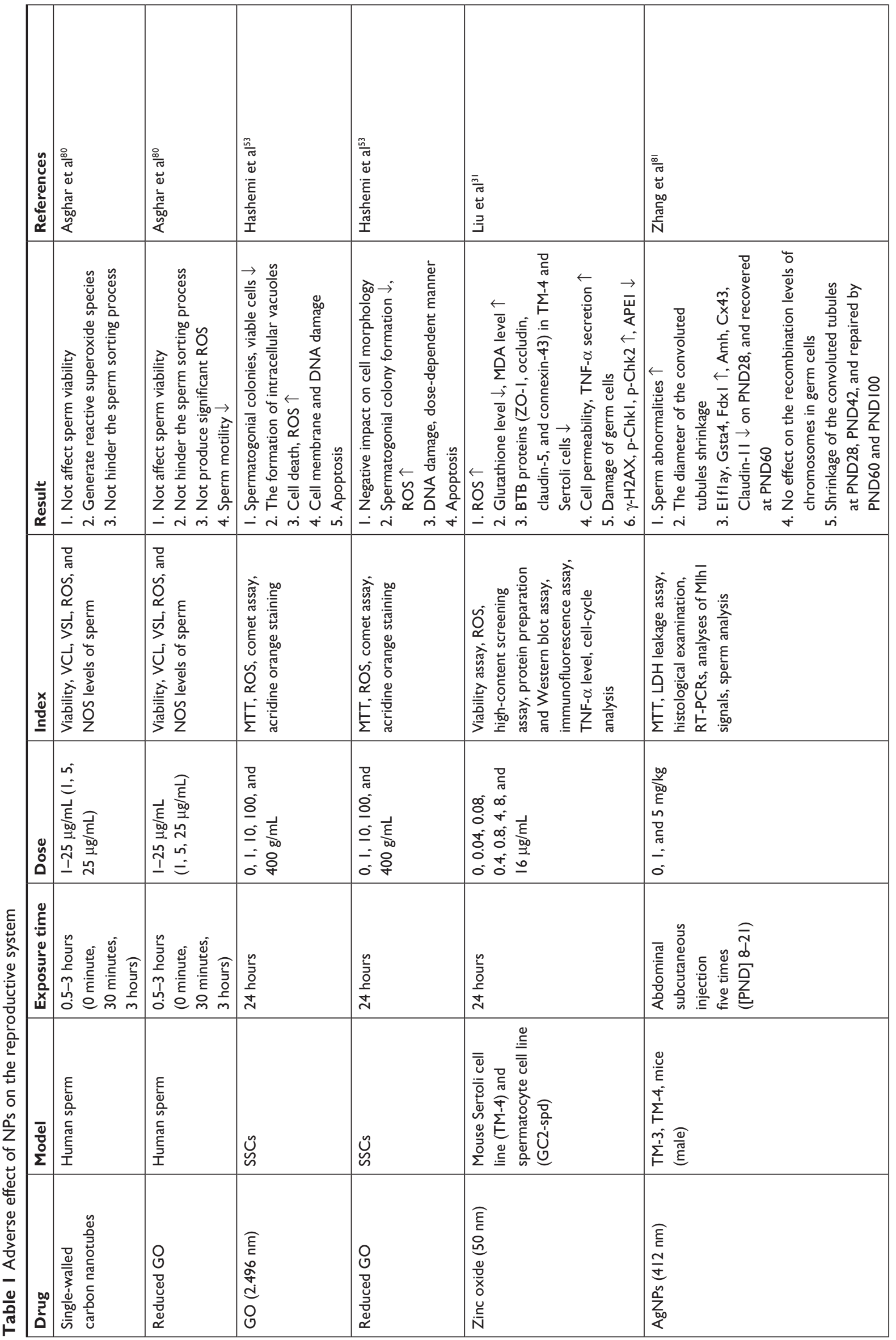




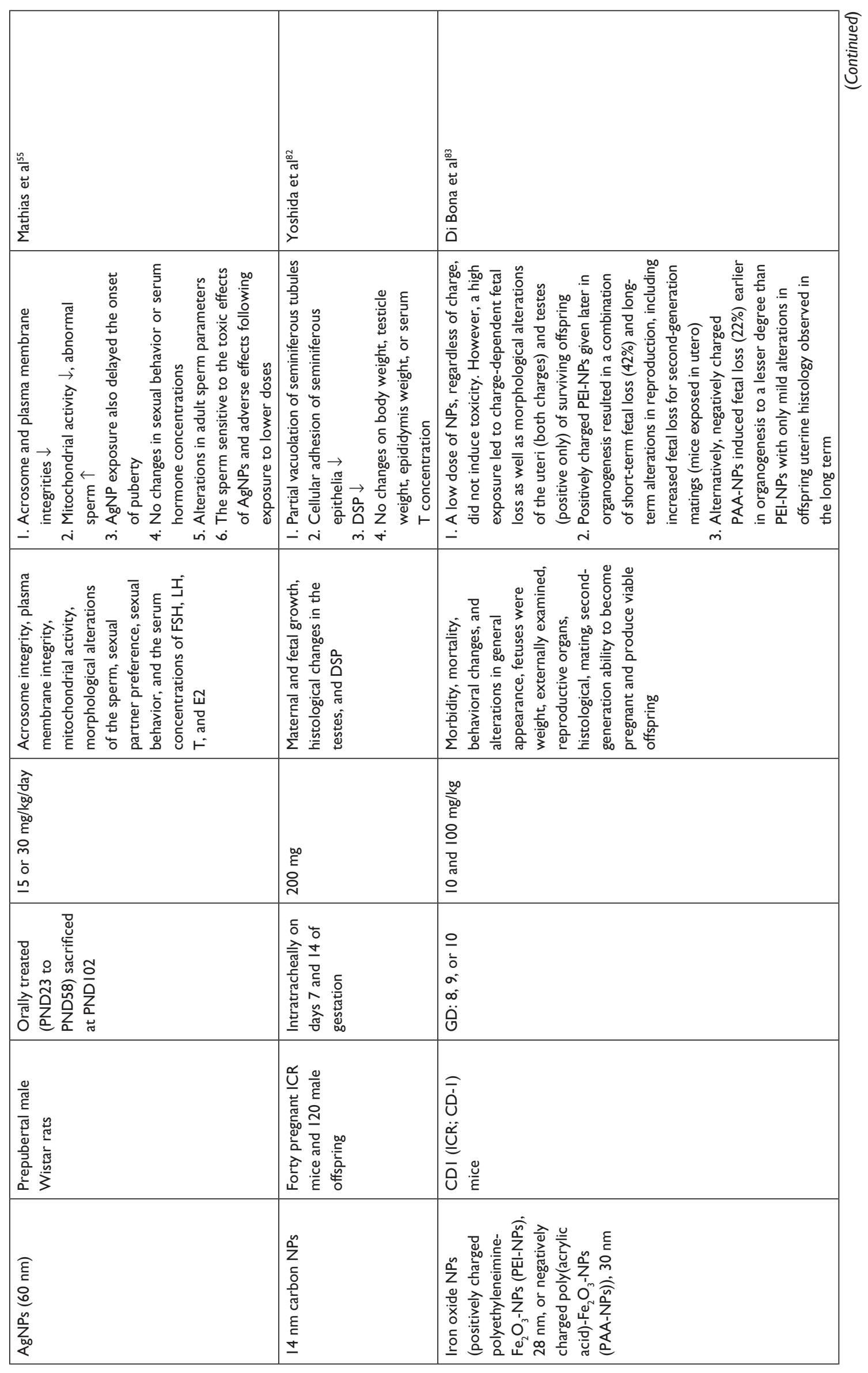




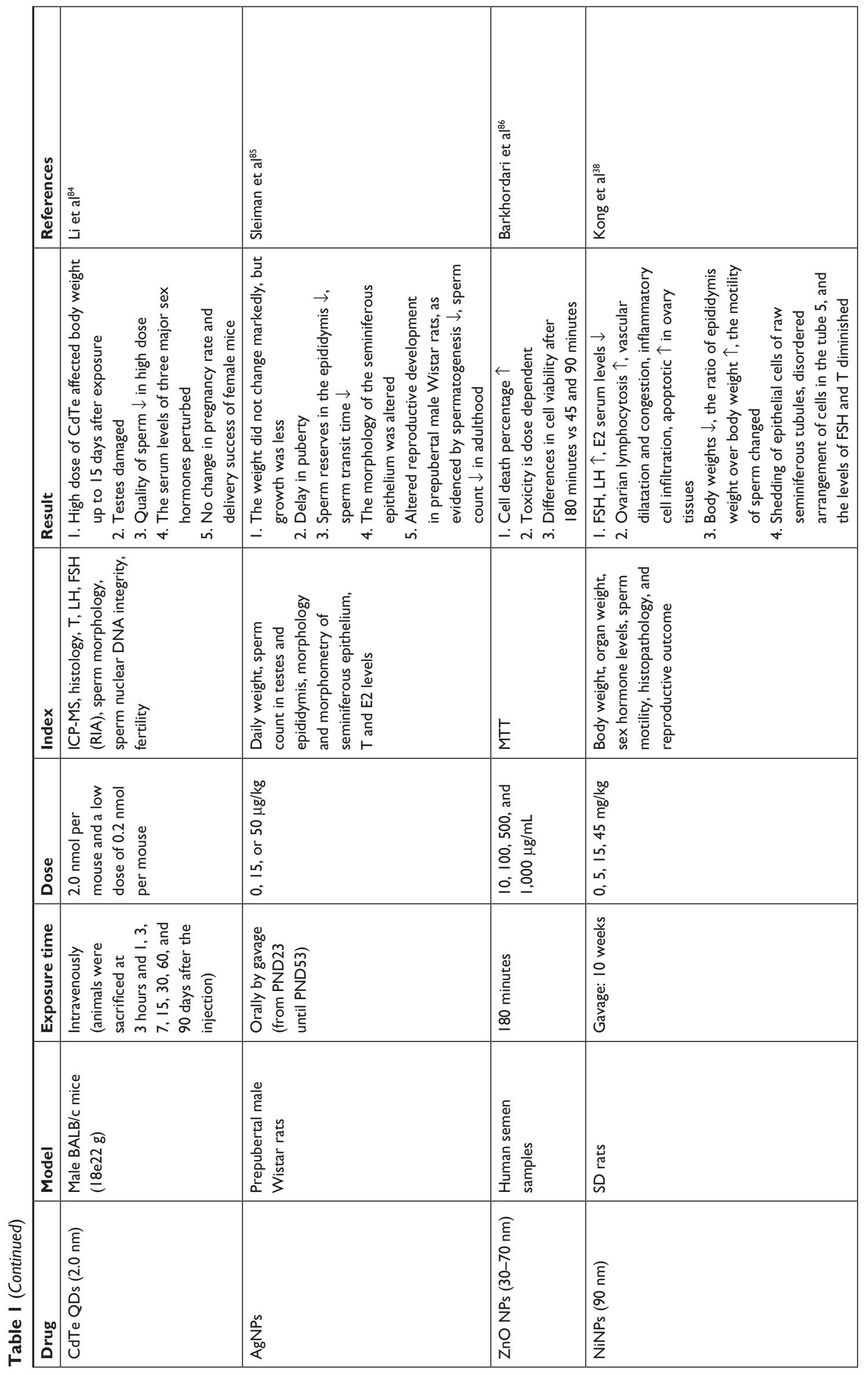




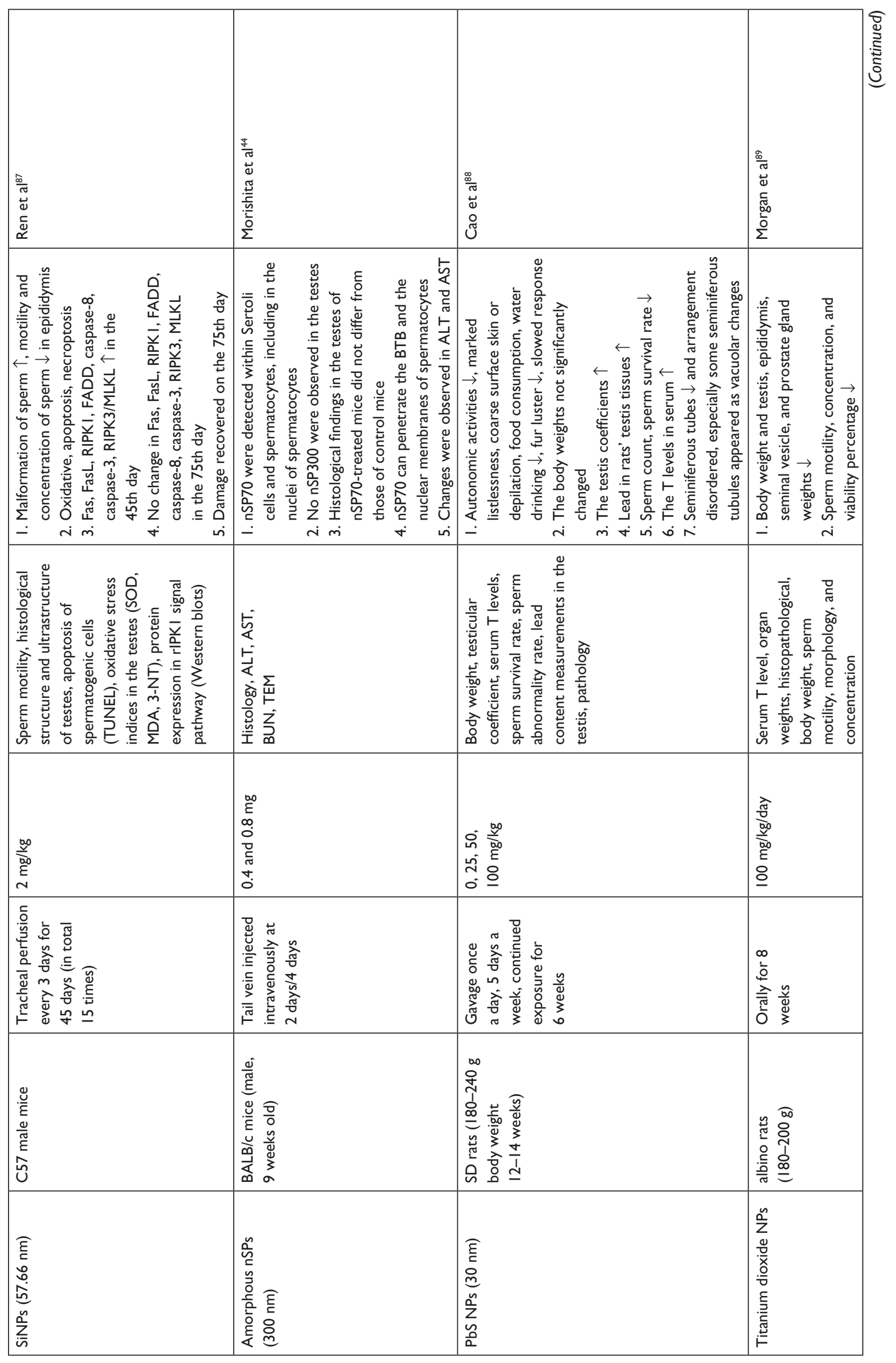




\begin{tabular}{|c|c|c|c|c|c|}
\hline 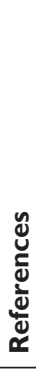 & & 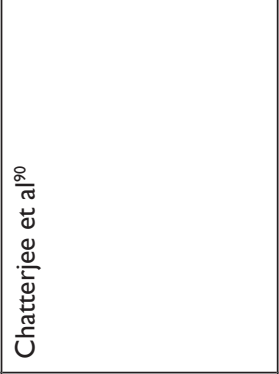 & 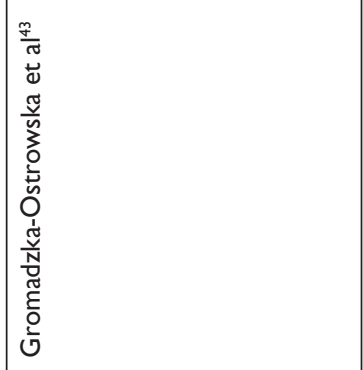 & 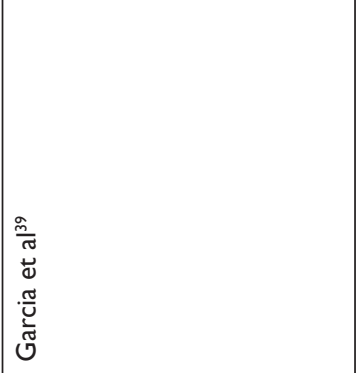 & \begin{tabular}{|l}
$\frac{\bar{\sigma}}{\bar{\sigma}}$ \\
$\overrightarrow{0}$ \\
$\overrightarrow{\bar{x}}$
\end{tabular} \\
\hline 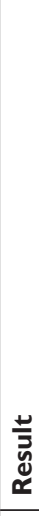 & 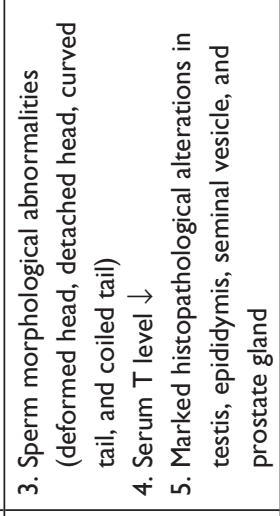 & 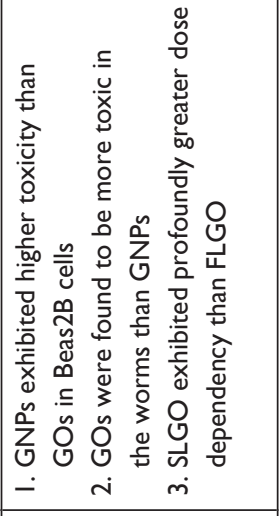 & 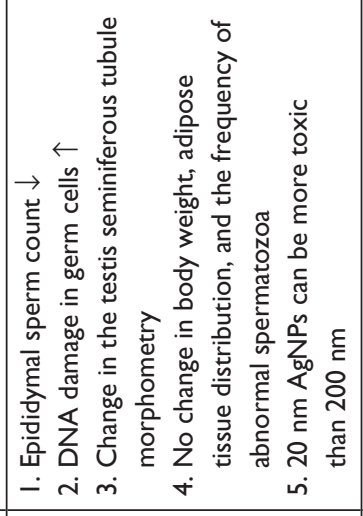 & 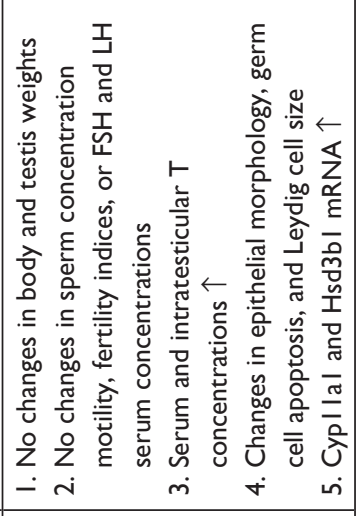 & 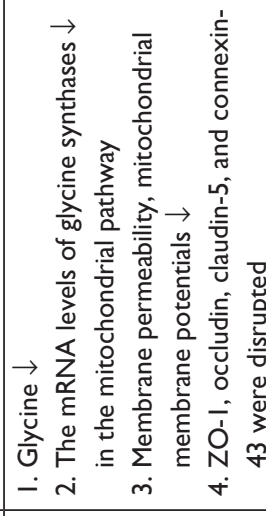 \\
\hline 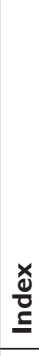 & & 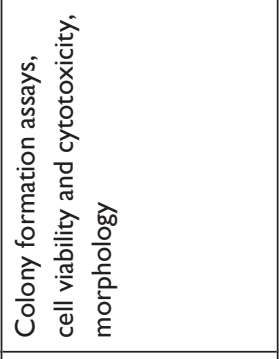 & 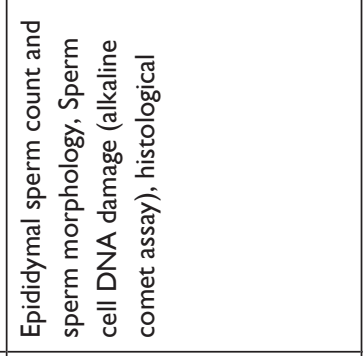 & 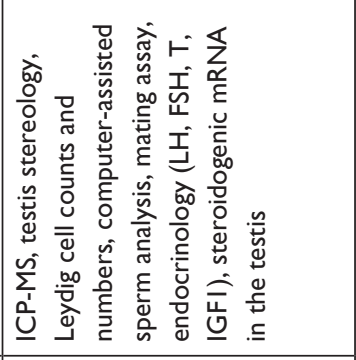 & 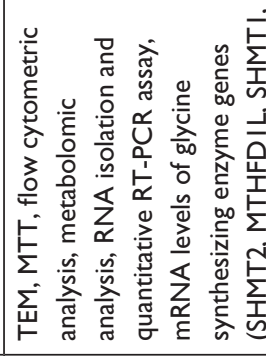 \\
\hline $\begin{array}{l}\text { ்ֻ } \\
\text { هั }\end{array}$ & & 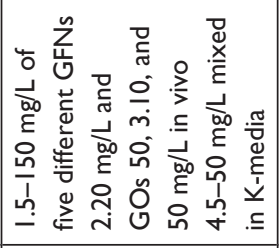 & 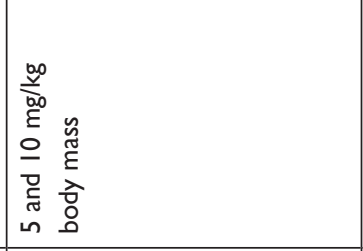 & 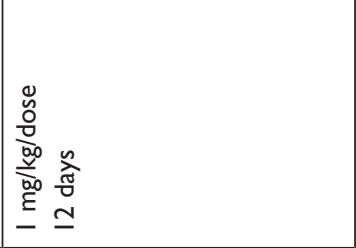 & $\mid \begin{array}{l}\sum \\
\leq \\
0 \\
0 \\
0 \\
0 \\
\vdots \\
\vdots \\
\\
0\end{array}$ \\
\hline 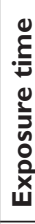 & & 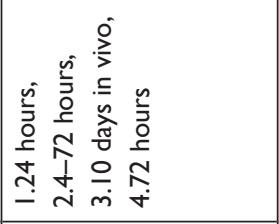 & 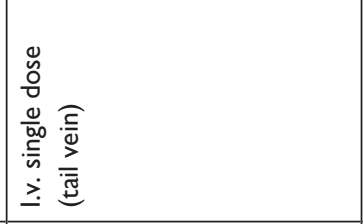 & 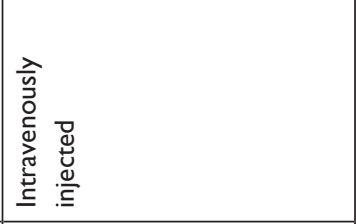 & 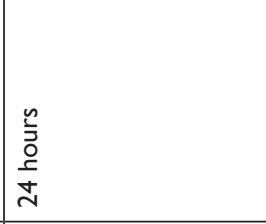 \\
\hline $\begin{array}{l}\bar{\Phi} \\
\frac{\delta}{\Sigma}\end{array}$ & & 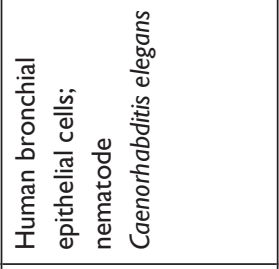 & 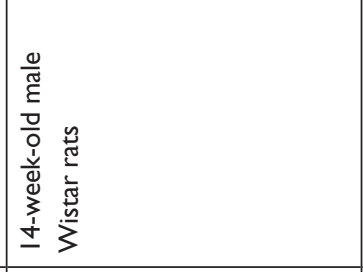 & $\overline{8}$ & 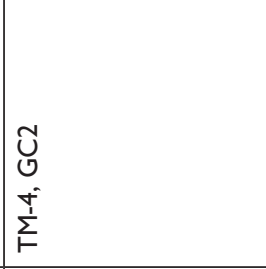 \\
\hline & & 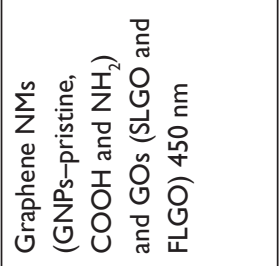 & 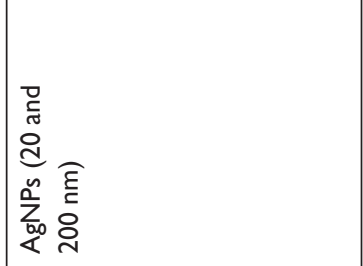 & 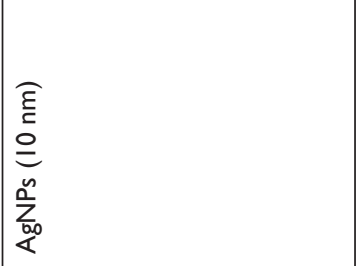 & 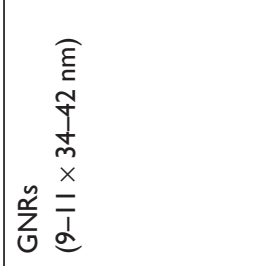 \\
\hline
\end{tabular}




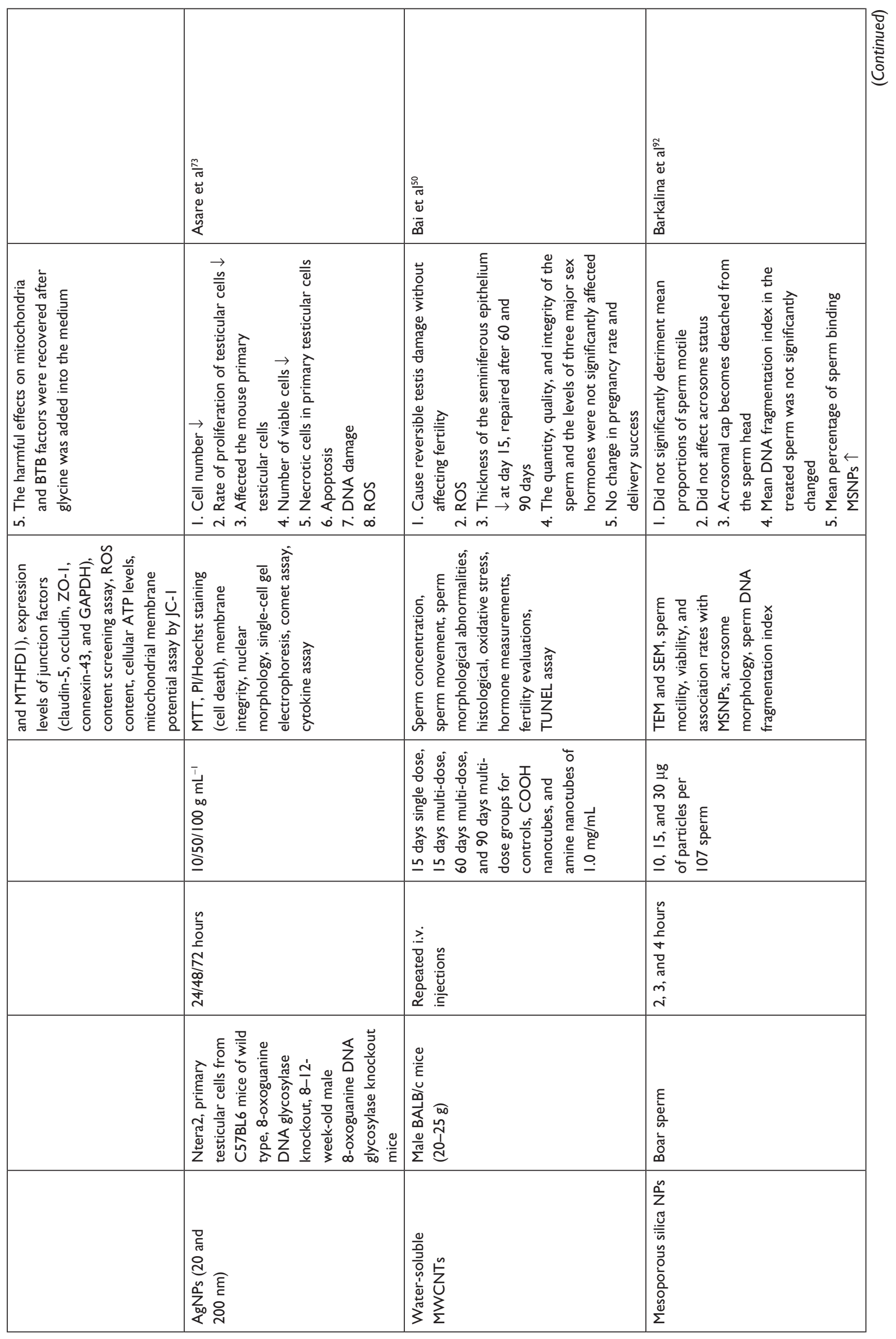




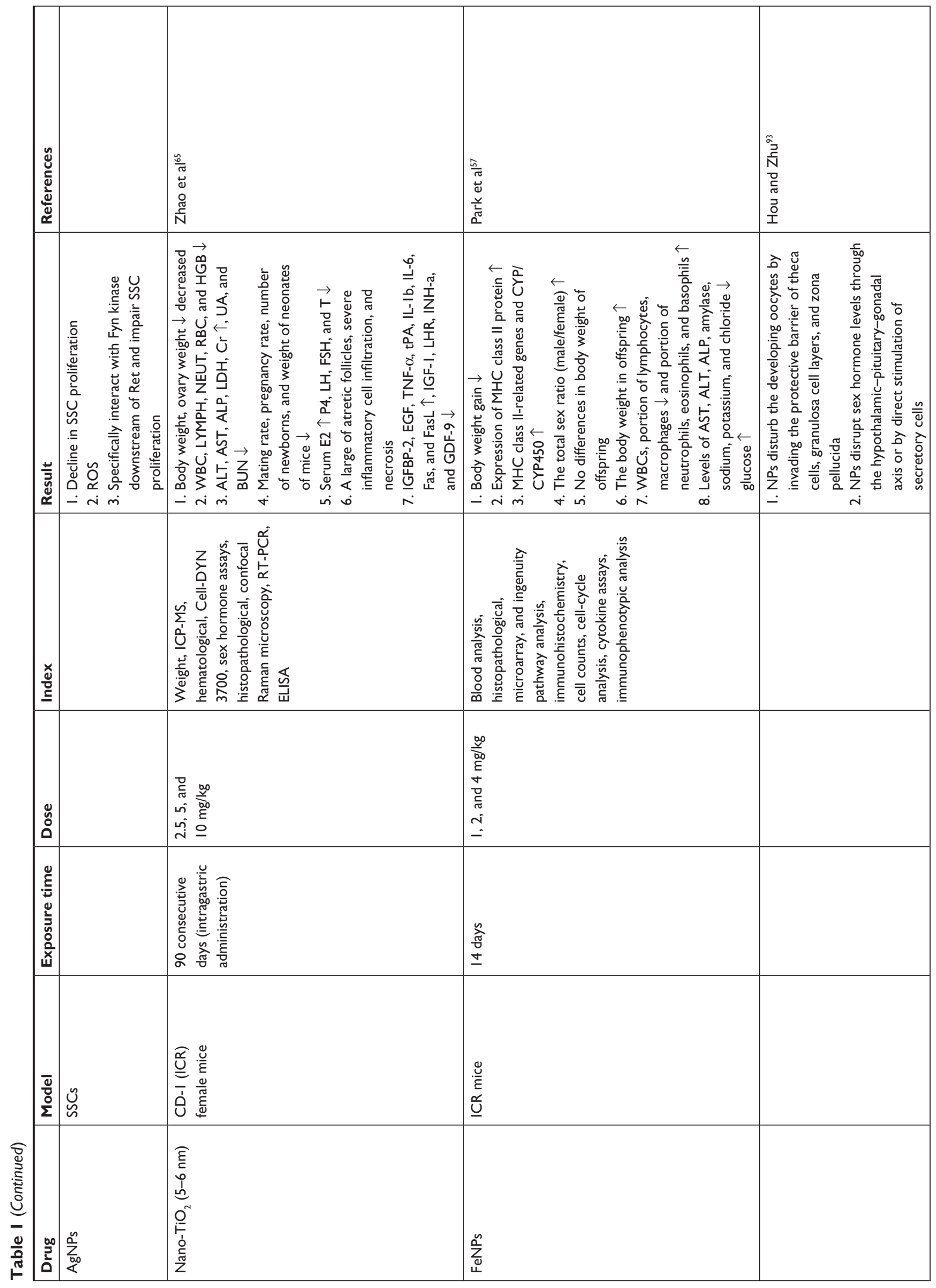




\begin{tabular}{|c|c|}
\hline & 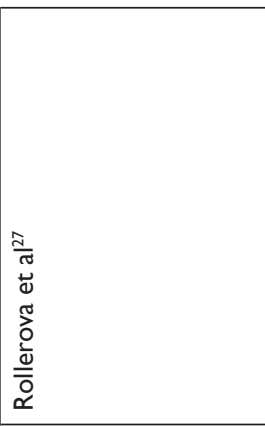 \\
\hline \multirow[t]{6}{*}{ 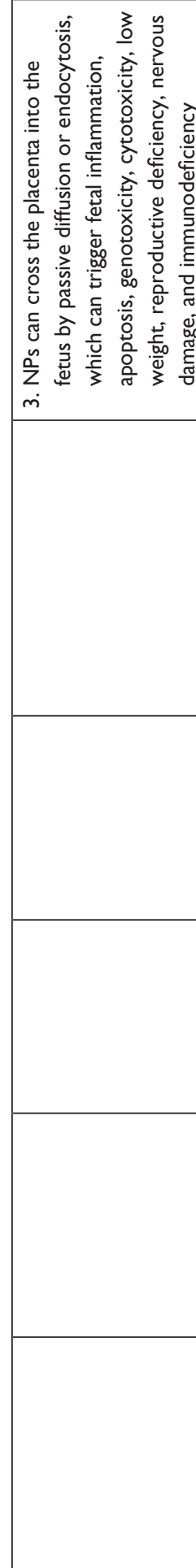 } & 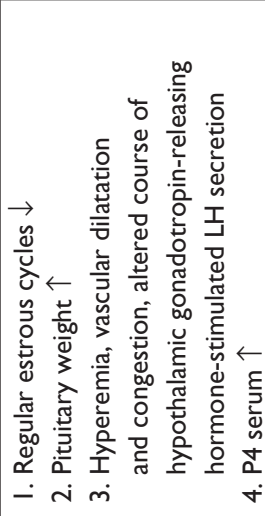 \\
\hline & 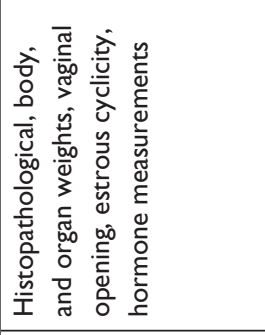 \\
\hline & 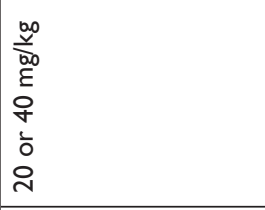 \\
\hline & 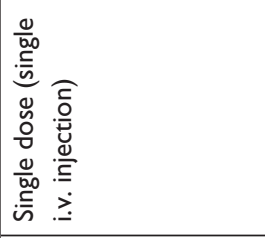 \\
\hline & 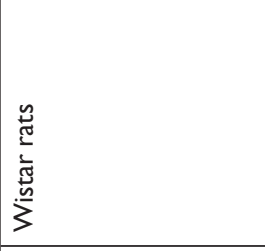 \\
\hline & 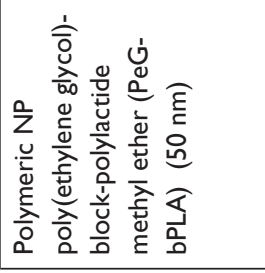 \\
\hline
\end{tabular}

of spermatocysts and ovarioles and in internal germ cells, leading to the induction of early germ cell death or malformations via complex mechanisms related to apoptosis and autophagy through mitochondrial and lysosomal pathways. ${ }^{72}$ AgNPs cause apoptosis, necrosis, and decreased proliferation and an increase in DNA strand breaks in NT2 cells. ${ }^{73}$

\section{Oxidative stress}

ROS and free radical species can damage sperm function and DNA integrity. Thus, oxidative stress has been considered one of the most important causes of male infertility. ${ }^{28}$ AgNP exposure has been associated with ROS production that can decrease mitochondrial activity in macrophages. The oxidative stress status was assessed by the levels of GSH and lipid peroxidation (MDA). GSH, as a marker of intracellular antioxidant capacity, was lower following treatment with ZnO NPs in both TM-4 cells and GC2-spd cells. However, increased MDA levels were found in TM-4 cells due to oxidative stress. ${ }^{31}$

$\mathrm{ZnO}$ NP-induced ROS could damage cell and organelle membranes. ZnO NPs can alter cell membrane permeability and affect the mitochondrial membrane potential. This review showed that ZnO NPs increased TM-4 cell membrane permeability and decreased mitochondrial membrane potential. The expression of claudin-5, occludin, ZO-1, and connexin-43 was significantly decreased. The damage caused by ZnO NPs could be partially reduced when treated with ROS inhibitor. These results suggest that $\mathrm{ZnO}$ NPs are able to induce ROS generation, cause damage to TM- 4 cells, and disrupt the integrity of the BTB. In addition to cytological changes, some molecular changes have also been discovered. NPs could increase Erk $1 / 2$ and TNF- $\alpha$, while pretreating the cells with $\mathrm{N}$-acetyl-L-cysteine (NAC) partially reversed this effect. ${ }^{31}$ Erk $1 / 2$ and TNF- $\alpha$ might be involved in the ROS induced by $\mathrm{ZnO}$ NPs. On the one hand, ROS might be due to the activation of ErK1/2 and TNF- $\alpha$, and, on the other hand, it could lead to the increase in Erk1/2 and TNF- $\alpha$. It can also cause apoptosis, inflammation, and DNA damage. However, more data should be gathered to reveal the relationship between ErK $1 / 2$ and TNF- $\alpha$ and ROS induced by NPs.

\section{Cell apoptosis}

Apoptosis is a process of programmed cell death that occurs in multicellular organisms to maintain homeostasis of the intracellular environment. The characteristics of this process are changes in morphology, cell death, and apoptotic bodies. Apoptotic bodies are cell fragments that are then phagocytosed by phagocytic cells before the cellular contents can 
damage the surrounding cells. Many studies have confirmed that NPs can induce apoptosis in cells. Furthermore, apoptosis of reproductive cells has recently been confirmed. A previous study showed that AgNPs decrease mitochondrial activity and lead to apoptosis and necrosis of germline stem cells. ${ }^{74}$ The literature also reports that some NPs can alter the expression of the $B A X$ and $B C L-2$ genes, which are controlled by apoptosis, but the results are not consistent. Silver NPs did not alter the gene expression of BAX and BCL-2. ${ }^{75}$ However, graphene was shown to activate Bim and Bax. The different results might be due to the different materials, particle sizes, and surface modifications. Apoptosis could be caused by the activation of the mitochondrial pathway due to the depletion of the mitochondrial membrane potential and increased ROS in the cells. The MAPK (JNK, ERK, and p38) and TGF- $\beta$ pathways were found to be activated in pristine-graphene-treated cells. These two pathways activated Bim and Bax as well as caspase-3 and its downstream effector proteins. ${ }^{76}$ However, this result was found in only one study, and the mechanism of how other NPs induce apoptosis requires further study.

\section{DNA damage}

As mentioned previously, NPs can cause oxidative stress and lead to DNA damage both in vivo and vitro. After exposure to $\mathrm{ZnO}$ NPs, $\gamma$-H2AX, p-Chk1, and p-Chk2 protein levels were increased, whereas APE1 protein expression was decreased in GC2-spd cells. When oxidative stress was inhibited, the expression of these genes was partially reversed. This result suggests that $\mathrm{ZnO}$ caused genetic changes and led to DNA damage, which is partially induced by ROS. ZnO NPs can also cause changes in the cell cycle through oxidative stress, increasing the number of cells in the S phase and upregulating the expression of cell-cycle proteins ${ }^{31} \gamma-\mathrm{H} 2 \mathrm{AX}$ is upregulated to repair damaged DNA, but ZnO NPs inhibit $\gamma$-H2AX expression in ovarian cells (CKO-K1 cells). Furthermore, $\mathrm{NF}-\kappa \mathrm{B}$ (p65) was significantly decreased by ZnO NPs. The impairment caused by ZnO NPs can be transmitted through cell generations; therefore, $\mathrm{ZnO}$ NPs can cause embryonic toxicity. ${ }^{66}$

The effects on reproduction are correlated with altered DNA methylation patterns in the germ line. Methylation of DNA is sensitive to environmental changes. NPs might directly induce DNA methylation, or NPs could lead to alterations in sex hormones, and the hormone alterations could lead to DNA methylation. ${ }^{78} \mathrm{TiO}_{2}$ NPs and AgNPs showed a tendency to cause DNA damage. ${ }^{73}$ In addition to autophagy and DNA damage, NPs could upregulate a series of pro-inflammatory genes such as TNF- $\alpha$, IL-1, IL-6, and IL-8, then activate NF- $\mathrm{B}$ signaling. This result indicated that NPs could cause inflammation. The inflammation could lead to ROS, and then cause DNA damage and apoptosis. ${ }^{79}$

\section{Other mechanisms}

Studies have found that various sources of NPs can enter the cell through endocytosis and accumulate in cells. Because NPs are foreign substances, they will be phagocytized by lysosomes, resulting in the aggregation of NPs in lysosomes and impairing the lysosomal degradation capacity through alkalinization of the lysosomal $\mathrm{pH}$. This process indicated that NPs could induce autophagy. Previous studies showed that AuNPs induced autophagy in germ cells. Upregulation of LC3 and downregulation of P62 can be found in gold AuNP-treated cells. The upregulation of LC3, an autophagy-related protein, indicates autophagy, whereas the downregulation of p62 indicates that autophagosome degradation is impeded..$^{77}$

\section{Limitations and prospects}

To date, the major weakness in the existing research is the almost purely descriptive understanding of results relating to the toxic effects of NPs, while the underlying mechanisms remain unclear. There are only a few studies about the interactions between NMs and biological matter on the molecular level; most of the research remains at the macrolevel. Thus, future studies should explore NP toxicity at the molecular level. The current studies of NP toxicity toward the reproductive system typically focus on individual alterations, but the connection between each individual alteration is rarely studied. Thus, further research should attempt a more in-depth examination of the molecular mechanisms of nanotoxicity and the interaction between each individual alteration. The investigations of reproductive toxicity are also imbalanced in gender. There are more studies on males than those on females. This may be because the female reproductive system is more complex than the male reproductive system and that the toxicity not only affects the parental generation but also the offspring.

The study of nanotoxicity is multidisciplinary and requires several levels of interdisciplinary research. During the last decade, much research has been performed to understand the effects of NMs used for various applications. Unfortunately, the current information about the effects of NMs on overall reproductive outcomes is still lacking. Therefore, long-term studies using animal models that are phylogenetically close to human 
beings and exposure conditions that reflect realistic scenarios regarding the dosages and routes of administration are needed. In addition, similar studies should be conducted for indicator species of sensitive ecosystems to estimate the impacts of NPs after intended or unintended release into the environment.

\section{Conclusion}

Currently, NMs are widely used in many aspects of our lives, and thus, our risk of exposure to NMs has increased. NPs can enter the body through several different routes and produce toxicity in different systems, including the reproductive system. NPs have been shown to detrimentally affect the reproductive systems of mice in vivo and in vitro. At the cellular level, NPs can induce infertility by altering the activity, morphology, quality, and quantity of sperm. In female reproductive cells, NPs can disturb primary and secondary follicle development, causing irregular cell arrangement and a shapeless follicular antrum. In addition, NPs can impact Leydig cell viability, proliferation, and gene expression. The toxicity of NPs is dose and size dependent, and for some NPs, the core structure and surface chemistry are also important. On the organ level, NPs can deposit in the ovary and testis, leading to weight decreases of the testis and epididymis and changes in the testis seminiferous tubule morphometry. On the body level, the levels of some hormones have been observed to change; for example, in male mice, the serum and intratesticular $\mathrm{T}$ levels have been shown to decrease. In females, increases in E2 and FSH and reductions in P4, $\mathrm{LH}$, and T were observed. Sexual behavior changes were not observed in males, whereas in females, one study showed a reduced number of regular estrous cycles. Furthermore, the mechanisms underlying all these alterations remain unclear. Oxidative stress-induced apoptosis caused by NP exposure is considered the main factor in the reproductive and developmental toxicity of NPs. The levels of GSH, lipid peroxidation (MDA), and GSH were increased after NP exposure, indicating increased ROS production. Apoptosis may be caused by NPs directly or as a result of ROS generation. The mechanism underlying the reproductive toxicity of NMs remains incompletely understood and must be investigated further to determine how NPs induce these effects and what occurs after ROS or apoptosis occurs.

\section{Acknowledgments}

This work was supported by the National Key Research and Development Program of China (2016YFC1102603, 2016YFC1102605), the National Natural Science Foundation of China (51672122), and the Natural Science Foundation of Guangdong Province (2015A030313299, 2016A030313673).

\section{Author contributions}

All authors made substantial contributions to conception and design, acquisition of data, or analysis and interpretation of data; took part in drafting the article or revising it critically for important intellectual content; gave final approval of the version to be published; and agree to be accountable for all aspects of the work.

\section{Disclosure}

The authors report no conflicts of interest in this work.

\section{References}

1. Ema M, Okuda H, Gamo M, Honda K. A review of reproductive and developmental toxicity of silver nanoparticles in laboratory animals. Reprod Toxicol. 2017;67:149-164.

2. Mcauliffe ME, Perry MJ. Are nanoparticles potential male reproductive toxicants? A literature review. Nanotoxicology. 2007;1(3): 204-210.

3. Schug TT, Nadadur SS, Johnson AF. Nano GO Consortium - a team science approach to assess engineered nanomaterials: reliable assays and methods. Environ Health Perspect. 2013;121(6):A176-A177.

4. Sharpe RM. The "oestrogen hypothesis" - where do we stand now? Int J Androl. 2003;26(1):2-15.

5. Lee JH, Huh YM, Jun YW, et al. Artificially engineered magnetic nanoparticles for ultra-sensitive molecular imaging. Nat Med. 2007;13(1): 95-99.

6. Suarasan S, Licarete E, Astilean S, Craciun AM. Probing cellular uptake and tracking of differently shaped gelatin-coated gold nanoparticles inside of ovarian cancer cells by two-photon excited photoluminescence analyzed by fluorescence lifetime imaging (FLIM). Colloids Surf B Biointerfaces. 2018;166:135-143.

7. Steuber N, Vo K, Wadhwa R, et al. Tocotrienol nanoemulsion platform of curcumin elicit elevated apoptosis and augmentation of anticancer efficacy against breast and ovarian carcinomas. Int J Mol Sci. 2016;17(11):1792.

8. Abou-Elnaga A, Mutawa G, El-Sherbiny IM, et al. Novel nanotherapeutic approach actively targets human ovarian cancer stem cells after xenograft into nude mice. Int J Mol Sci. 2017;18(4):813.

9. Nohynek GJ, Lademann J, Ribaud C, Roberts MS. Grey goo on the skin? Nanotechnology, cosmetic and sunscreen safety. Crit Rev Toxicol. 2007;37(3):251-277.

10. Sadrieh N, Wokovich AM, Gopee NV, et al. Lack of significant dermal penetration of titanium dioxide from sunscreen formulations containing nano- and submicron-size $\mathrm{TiO}_{2}$ particles. Toxicol Sci. 2010;115(1): 156-166.

11. Kiss B, Bíró T, Czifra G, et al. Investigation of micronized titanium dioxide penetration in human skin xenografts and its effect on cellular functions of human skin-derived cells. Exp Dermatol. 2008;17(8): 659-667.

12. Dussert AS, Gooris E, Hemmerle J. Characterization of the mineral content of a physical sunscreen emulsion and its distribution onto human stratum corneum. Int J Cosmet Sci. 1997;19(3):119-129.

13. Mavon A, Miquel C, Lejeune O, Payre B, Moretto P. In vitro percutaneous absorption and in vivo stratum corneum distribution of an organic and a mineral sunscreen. Skin Pharmacol Physiol. 2007;20(1):10-20. 
14. Teichmann A, Pissavini M, Ferrero L, et al. Investigation of the homogeneity of the distribution of sunscreen formulations on the human skin: characterization and comparison of two different methods. J Biomed Opt. 2006;11(6):064005.

15. Vance ME, Kuiken T, Vejerano EP, et al. Nanotechnology in the real world: redeveloping the nanomaterial consumer products inventory. Beilstein J Nanotechnol. 2015;6:1769-1780.

16. Rincker MJ, Hill GM, Link JE, Meyer AM, Rowntree JE. Effects of dietary zinc and iron supplementation on mineral excretion, body composition, and mineral status of nursery pigs. J Anim Sci. 2005; 83(12):2762-2774.

17. Jani PU, Mccarthy DE, Florence AT. Titanium dioxide (rutile) particle uptake from the rat GI tract and translocation to systemic organs after oral administration. Int J Pharm. 1994;105(2):157-168.

18. Geraets L, Oomen AG, Krystek P. Tissue distribution and elimination after oral and intravenous administration of different titanium dioxide nanoparticles in rats. Part Fibre Toxicol. 2014;11:30.

19. Geraets L, Oomen AG, Schroeter JD, Coleman VA, Cassee FR. Tissue distribution of inhaled micro- and nano-sized cerium oxide particles in rats: results from a 28-day exposure study. Toxicol Sci. 2012;127(2): 463-473.

20. Mostafalou S, Mohammadi H, Ramazani A, Abdollahi M. Different biokinetics of nanomedicines linking to their toxicity; an overview. Daru. 2013;21(1):14.

21. Lankveld DP, Oomen AG, Krystek P, et al. The kinetics of the tissue distribution of silver nanoparticles of different sizes. Biomaterials. 2010;31(32):8350-8361.

22. Lankveld DP, Rayavarapu RG, Krystek P, et al. Blood clearance and tissue distribution of PEGylated and non-PEGylated gold nanorods after intravenous administration in rats. Nanomedicine. 2011;6(2):339-349.

23. de Jong WH, Hagens WI, Krystek P, Burger MC, Sips AJ, Geertsma RE. Particle size-dependent organ distribution of gold nanoparticles after intravenous administration. Biomaterials. 2008;29(12):1912-1919.

24. Sadauskas E, Jacobsen NR, Danscher G, et al. Biodistribution of gold nanoparticles in mouse lung following intratracheal instillation. Chem Cent J. 2009;3:16.

25. Buzea C, Pacheco II, Robbie K. Nanomaterials and nanoparticles: sources and toxicity. Biointerphases. 2007;2(4):MR17-MR71.

26. Longmire M, Choyke PL, Kobayashi H. Clearance properties of nanosized particles and molecules as imaging agents: considerations and caveats. Nanomedicine. 2008;3(5):703-717.

27. Rollerova E, Jurcovicova J, Mlynarcikova A, et al. Delayed adverse effects of neonatal exposure to polymeric nanoparticle poly(ethylene glycol)-block-polylactide methyl ether on hypothalamic-pituitaryovarian axis development and function in Wistar rats. Reprod Toxicol. 2015;57:165-175.

28. Hussein M, Ali HA, Saadeldin IM, Ahmed MM. Quercetin alleviates zinc oxide nanoreprotoxicity in male albino rats. $J$ Biochem $\mathrm{Mol}$ Toxicol. 2016;30(10):489-496.

29. Araujo L, Sheppard M, Löbenberg R, Kreuter J. Uptake of PMMA nanoparticles from the gastrointestinal tract after oral administration to rats: modification of the body distribution after suspension in surfactant solutions and in oil vehicles. Int J Pharm. 1999;176(2):209-224.

30. Kim JS, Yoon TJ, Yu KN, et al. Toxicity and tissue distribution of magnetic nanoparticles in mice. Toxicol Sci. 2006;89(1):338-347.

31. Liu Q, Xu C, Ji G, et al. Sublethal effects of zinc oxide nanoparticles on male reproductive cells. Toxicol In Vitro. 2016;35:131-138.

32. Muoth C, Aengenheister L, Kucki M, Wick P, Buerki-Thurnherr T. Nanoparticle transport across the placental barrier: pushing the field forward! Nanomedicine. 2016;11(8):941-957.

33. Philbrook NA, Winn LM, Afrooz AR, Saleh NB, Walker VK. The effect of $\mathrm{TiO}(2)$ and $\mathrm{Ag}$ nanoparticles on reproduction and development of Drosophila melanogaster and CD-1 mice. Toxicol Appl Pharmacol. 2011;257(3):429-436.

34. Taylor U, Barchanski A, Garrels W, et al. Toxicity of gold nanoparticles on somatic and reproductive cells. Adv Exp Med Biol. 2012;733: 125-133.
35. Zhao H, Gu W, Ye L, Yang H. Biodistribution of PAMAM dendrimer conjugated magnetic nanoparticles in mice. J Mater Sci Mater Med. 2014;25(3):769-776.

36. Morgan AM, Ibrahim MA, Noshy PA. Reproductive toxicity provoked by titanium dioxide nanoparticles and the ameliorative role of Tiron in adult male rats. Biochem Biophys Res Commun. 2017;486(2):595-600.

37. Leclerc L, Klein J, Forest V, et al. Testicular biodistribution of silica-gold nanoparticles after intramuscular injection in mice. Biomed Microdevices. 2015;17(4):66.

38. Kong L, Tang M, Zhang T, et al. Nickel nanoparticles exposure and reproductive toxicity in healthy adult rats. Int J Mol Sci. 2014;15(11): 21253-21269

39. Garcia TX, Costa GM, França LR, Hofmann MC. Sub-acute intravenous administration of silver nanoparticles in male mice alters Leydig cell function and testosterone levels. Reprod Toxicol. 2014;45:59-70.

40. Nirmal NK, Awasthi KK, John PJ. Effects of nano-graphene oxide on testis, epididymis and fertility of Wistar rats. Basic Clin Pharmacol Toxicol. 2017;121(3):202-210.

41. Manin OI, Nikolaev VA, Kolomirtsev AA, Lebedenko IIu. Comparative toxicological evaluation of domestic golden alloys for soldering. Stomatologiia. 2007;86(1):64-67.

42. Adebayo OA, Akinloye O, Adaramoye OA. Cerium oxide nanoparticle elicits oxidative stress, endocrine imbalance and lowers sperm characteristics in testes of Balb/c mice. Andrologia. 2018;50(3):e12920.

43. Gromadzka-Ostrowska J, Dziendzikowska K, Lankoff A, et al. Silver nanoparticles effects on epididymal sperm in rats. Toxicol Lett. 2012; 214(3):251-258.

44. Morishita Y, Yoshioka Y, Satoh H, et al. Distribution and histologic effects of intravenously administered amorphous nanosilica particles in the testes of mice. Biochem Biophys Res Commun. 2012;420(2): 297-301.

45. Shahin NN, Mohamed MM. Nano-sized titanium dioxide toxicity in rat prostate and testis: possible ameliorative effect of morin. Toxicol Appl Pharmacol. 2017;334:129-141.

46. Nazem H, Arefian Z. Effect of ZnO NPs on tumor marker hormones in male rats. Biomed Res-India. 2015;26:82-88.

47. Mauduit C, Gasnier F, Rey C, et al. Tumor necrosis factor-alpha inhibits Leydig cell steroidogenesis through a decrease in steroidogenic acute regulatory protein expression. Endocrinology. 1998;139(6): 2863-2868.

48. Sherins RJ, Hodgen GD. Testicular gamma glutamyl-transpeptidase: an index of Sertoli cell function in man. J Reprod Fertil. 1976;48(1): 191-193.

49. Lafuente D, Garcia T, Blanco J, et al. Effects of oral exposure to silver nanoparticles on the sperm of rats. Reprod Toxicol. 2016;60:133-139.

50. Bai Y, Zhang Y, Zhang J, et al. Repeated administrations of carbon nanotubes in male mice cause reversible testis damage without affecting fertility. Nat Nanotechnol. 2010;5(9):683-689.

51. Komatsu T, Tabata M, Kubo-Irie M, et al. The effects of nanoparticles on mouse testis Leydig cells in vitro. Toxicol In Vitro. 2008;22(8): 1825-1831.

52. Braydich-Stolle LK, Lucas B, Schrand A, et al. Silver nanoparticles disrupt GDNF/Fyn kinase signaling in spermatogonial stem cells. Toxicol Sci. 2010;116(2):577-589.

53. Hashemi E, Akhavan O, Shamsara M, Daliri M, Dashtizad M, Farmany A. Synthesis and cyto-genotoxicity evaluation of graphene on mice spermatogonial stem cells. Colloids Surf B Biointerfaces. 2016; 146:770-776.

54. Lafuente D, Garcia T, Blanco J, et al. Effects of oral exposure to silver nanoparticles on the sperm of rats. Reprod Toxicol. 2016;60:133-139.

55. Mathias FT, Romano RM, Kizys MM, Kasamatsu T, Giannocco G. Daily exposure to silver nanoparticles during prepubertal development decreases adult sperm and reproductive parameters. Nanotoxicology. 2015;9(1):64-70

56. Li C, Taneda S, Taya K, et al. Effects of in utero exposure to nanoparticle-rich diesel exhaust on testicular function in immature male rats. Toxicol Lett. 2009;185(1):1-8. 
57. Park EJ, Jeong U, Kim Y, Lee BS, Cho MH, Go YS. Deleterious effects in reproduction and developmental immunity elicited by pulmonary iron oxide nanoparticles. Environ Res. 2017;152:503-513.

58. Boudreau MD, Imam MS, Paredes AM, et al. Differential effects of silver nanoparticles and silver ions on tissue accumulation, distribution, and toxicity in the Sprague Dawley rat following daily oral gavage administration for 13 weeks. Toxicol Sci. 2016;150(1):131-160.

59. Schädlich A, Hoffmann S, Mueller T, et al. Accumulation of nanocarriers in the ovary: a neglected toxicity risk? J Control Rel. 2012; 160(1):105-112.

60. Lim JH, Kim SH, Lee IC, et al. Evaluation of maternal toxicity in rats exposed to multi-wall carbon nanotubes during pregnancy. Environ Health Toxicol. 2011;26:e2011006.

61. Semmler-Behnke M, Lipka J, Wenk A, et al. Size dependent translocation and fetal accumulation of gold nanoparticles from maternal blood in the rat. Part Fibre Toxicol. 2014;11:33.

62. Jo E, Seo G, Kwon JT, et al. Exposure to zinc oxide nanoparticles affects reproductive development and biodistribution in offspring rats. J Toxicol Sci. 2013;38(4):525-530.

63. Raj A, Shah P, Agrawal N. Dose-dependent effect of silver nanoparticles (AgNPs) on fertility and survival of Drosophila: an in-vivo study. PLoS One. 2017;12(5):e0178051.

64. Gao G, Ze Y, Li B, et al. Ovarian dysfunction and gene-expressed characteristics of female mice caused by long-term exposure to titanium dioxide nanoparticles. J Hazard Mater. 2012;243:19-27.

65. Zhao X, Yuguan Z, Gao G, Sang X, Li B. Nanosized TiO-induced reproductive system dysfunction and its mechanism in female mice. PLoS One. 2013;8(4):e59378.

66. Liu J, Zhao Y, Ge W, et al. Oocyte exposure to $\mathrm{ZnO}$ nanoparticles inhibits early embryonic development through the $\gamma-\mathrm{H} 2 \mathrm{AX}$ and NF- $\kappa \mathrm{B}$ signaling pathways. Oncotarget. 2017;8(26):42673-42692.

67. Hougaard KS, Jackson P, Kyjovska ZO, et al. Effects of lung exposure to carbon nanotubes on female fertility and pregnancy. A study in mice. Reprod Toxicol. 2013;41:86-97.

68. Ema M, Hougaard KS, Kishimoto A, Honda K. Reproductive and developmental toxicity of carbon-based nanomaterials: a literature review. Nanotoxicology. 2016;10(4):391-412.

69. Li Y, Zhang Y, Yan B. Nanotoxicity overview: nano-threat to susceptible populations. Int J Mol Sci. 2014;15(3):3671-3697.

70. Juch H, Nikitina L, Debbage P, Dohr G, Gauster M. Nanomaterial interference with early human placenta: sophisticated matter meets sophisticated tissues. Reprod Toxicol. 2013;41:73-79.

71. Mangalampalli B, Dumala N, Grover P. Acute oral toxicity study of magnesium oxide nanoparticles and microparticles in female albino Wistar rats. Regul Toxicol Pharmacol. 2017;90:170-184.

72. Yan S, Xing R, Zhou Y, et al. Reproductive toxicity and gender differences induced by cadmium telluride quantum dots in an invertebrate model organism. Sci Rep-Uk. 2016;6:34182.

73. Asare N, Instanes C, Sandberg WJ, et al. Cytotoxic and genotoxic effects of silver nanoparticles in testicular cells. Toxicology. 2012;291(1-3): 65-72.

74. Braydich-Stolle L, Hussain S, Schlager JJ, Hofmann MC. In vitro cytotoxicity of nanoparticles in mammalian germline stem cells. Toxicol Sci. 2005;88(2):412-419.

75. Degger N, Tse AC, Wu RS, Ack T, Rss W. Silver nanoparticles disrupt regulation of steroidogenesis in fish ovarian cells. Aquat Toxicol. 2015;169:143-151.

76. Li Y, Liu Y, Fu Y, et al. The triggering of apoptosis in macrophages by pristine graphene through the MAPK and TGF-beta signaling pathways. Biomaterials. 2012;33(2):402-411.

77. Ma X, Wu Y, Jin S, et al. Gold nanoparticles induce autophagosome accumulation through size-dependent nanoparticle uptake and lysosome impairment. ACS Nano. 2011;5(11):8629-8639.
78. Anway MD, Cupp AS, Uzumcu M, Skinner MK. Epigenetic transgenerational actions of endocrine disruptors and male fertility. Science. 2005;308(5727):1466-1469.

79. Khanna P, Ong C, Bay BH, Baeg GH. Nanotoxicity: an interplay of oxidative stress, inflammation and cell death. Nanomaterials. 2015; 5(3):1163-1180

80. Asghar W, Shafiee H, Velasco V, et al. Toxicology study of singlewalled carbon nanotubes and reduced graphene oxide in human sperm. Sci Rep. 2016;6:30270.

81. Zhang XF, Gurunathan S, Kim JH. Effects of silver nanoparticles on neonatal testis development in mice. Int $J$ Nanomedicine. 2015;10:6243-6256.

82. Yoshida S, Hiyoshi K, Oshio S, Takano H, Takeda K, Ichinose T. Effects of fetal exposure to carbon nanoparticles on reproductive function in male offspring. Fertil Steril. 2010;93(5):1695-1699.

83. Di Bona KR, Xu Y, Gray M. Short- and long-term effects of prenatal exposure to iron oxide nanoparticles: influence of surface charge and dose on developmental and reproductive toxicity. Int J Mol Sci. 2015;16(12):30251-30268.

84. Li X, Yang X, Yuwen L, Yang W, Weng L, Teng Z, Wang L. Evaluation of toxic effects of CdTe quantum dots on the reproductive system in adult male mice. Biomaterials. 2016;96:24-32.

85. Sleiman HK, Romano RM, Oliveira CA, Romano MA. Effects of prepubertal exposure to silver nanoparticles on reproductive parameters in adult male Wistar rats. $J$ Toxicol Environ Health A. 2013;76(17):1023-1032.

86. Barkhordari A, Hekmatimoghaddam S, Jebali A, Ali Khalili M, Talebi A, Noorani M. Effect of zinc oxide nanoparticles on viability of human spermatozoa. Iran J Reprod Med. 2013;11(9):767-771.

87. Ren L, Zhang J, Zou Y, et al. Silica nanoparticles induce reversible damage of spermatogenic cells via RIPK1 signal pathways in C57 mice. Int $J$ Nanomedicine. 2016;11:2251-2264.

88. Cao Y, Wang D, Li Q, Deng H, Shen J, Zheng G, Sun M. Rat testis damage caused by lead sulfide nanoparticles after oral exposure. J Nanosci Nanotechnol. 2016;16(3):2378-2383.

89. Morgan AM, Abd El-Hamid MI, Noshy PA. Reproductive toxicity investigation of titanium dioxide nanoparticles in male albino rats. Journal of Pharmacy and Pharmaceutical Sciences. 2015;4(10):34-49.

90. Chatterjee N, Yang JS, Park K, Oh SM, Park J, Choi J. Screening of toxic potential of graphene family nanomaterials using in vitro and alternative in vivo toxicity testing systems. Environ Health Toxicol. 2015;30:e2015007.

91. Xu B, Chen M, Ji X. Metabolomic profiles delineate the potential role of glycine in gold nanorod-induced disruption of mitochondria and bloodtestis barrier factors in TM-4 cells. Nanoscale. 2014;6:8265-8273.

92. Barkalina N, Jones C, Kashir J, et al. Effects of mesoporous silica nanoparticles upon the function of mammalian sperm in vitro. Nanomedicine. 2014;10(4):859-870.

93. Hou CC, Zhu JQ. Nanoparticles and female reproductive system: how do nanoparticles affect oogenesis and embryonic development. Oncotarget. 2017;8(65):109799-109817.

94. Myllynen P, Vähäkangas K. Placental transfer and metabolism: an overview of the experimental models utilizing human placental tissue. Toxicol In Vitro. 2013;27(1):507-512.

95. Chen S, Allam J, Duan Y, Haidl G. Influence of reactive oxygen species on human sperm functions and fertilizing capacity including therapeutical approaches. Arch Gynecol Obstet. 2013;288:191-199. 


\section{Publish your work in this journal}

The International Journal of Nanomedicine is an international, peerreviewed journal focusing on the application of nanotechnology in diagnostics, therapeutics, and drug delivery systems throughout the biomedical field. This journal is indexed on PubMed Central, MedLine, CAS, SciSearch $\AA$, Current Contents $\AA /$ Clinical Medicine,

Journal Citation Reports/Science Edition, EMBase, Scopus and the Elsevier Bibliographic databases. The manuscript management system is completely online and includes a very quick and fair peer-review system, which is all easy to use. Visit http://www.dovepress.com/ testimonials.php to read real quotes from published authors.

Submit your manuscript here: http://www.dovepress.com/international-journal-of-nanomedicine-journal 